\title{
O protagonismo da leitura no projeto de formação integralista: livros no jornal Flamma Verde - Florianópolis (SC) - entre 1936-1938
}

\section{The leading role of reading in the integralist action project: books in the newspaper Flamma Verde - Florianópolis (SC) - between 1936-1938}

https://doi.org/10.34112/2317-0972a2017V35n69p57-72

Gustavo Tiengo Pontes ${ }^{1}$

Maria Teresa Santos Cunha ${ }^{2}$

Resumo: O objetivo deste artigo é dar visibilidade à coluna "Bibliografia", publicada no jornal integralista Flamma Verde, editado em Florianópolis (SC) entre 1936-1938. Nessa coluna, constante em diversas edições desse jornal, foi indicada uma série de livros que apresentavam breves comentários cujo objetivo era "controlar" mais de perto a leitura e seus sentidos ligados ao projeto de formação integralista. A partir da análise de algumas dessas obras e de seus comentários, busca-se tecer considerações sobre aspectos relativos ao modelo de formação posto em circulação pela difusão dessa série de livros.

PALAVRAS-ChAVE: Livros; leitura; Ação Integralista Brasileira.

ABStRACT: This article aim is to give visibility to the column "Bibliografia", published in the integralist newspaper Flamma Verde elaborated in Florianópolis (SC) between 1936-1938. This column, published in many of these newspaper editions, indicated a series of books with brief comments that intended to "control", in a closer way, its reading and the senses related to the integralist action project. Through the analysis of some of those books and its comments, we intend to discuss the formation model disseminated in this series of books.

KEYWORDS: Books; reading; Brazilian Integralist Action.

1. Universidade Federal de Santa Catarina, Florianópolis, SC, Brasil.

2. Universidade do Estado de Santa Catarina, Florianópolis, SC, Brasil. 
O protagonismo da leitura no projeto de formação integralista...

Da escrita de um texto até o livro chegar às mãos de seus leitores, existe um circuito no qual diversos sujeitos buscam controlar mais de perto a produção do sentido da leitura, conforme observado por Roger Chartier, em diversos de seus estudos. Na obra $A$ ordem dos livros, o historiador francês comenta que o autor, o livreiro-editor, o comentador e o censor atuam a fim de confrontar o leitor com uma série de constrangimentos e regras. Por outro lado, o mesmo assevera: "a leitura é, por definição, rebelde e vadia” (CHARTIER, 1998, p. 7). Na mesma perspectiva, o historiador estadunidense Roberto Darnton investiga e elabora a noção "Circuito das Comunicações", com o objetivo de discutir a trajetória dos textos em livros até o final desse circuito com os leitores. Desde o editor, os gráficos, os livreiros, encadernadores etc., todos estão envolvidos no processo de transformação de textos em livros e contribuem para "esta tensão entre a coerção do texto sobre o leitor, bem como a liberdade do leitor com o texto" (DARNTON, 2010, p. 46).

Apesar de esses dois estudiosos tratarem de contextos e situações distintos do objeto proposto neste artigo, essa reflexão relacionada à escrita e à leitura é um pressuposto da abordagem do presente estudo. Esta investigação pretende dar visibilidade, por meio de seu estudo, a uma coluna de indicação de livros do periódico de orientação integralista Flamma Verde, editado em Florianópolis (SC), entre setembro de 1936 e fevereiro de 1938. Essa coluna intitulava-se "Bibliografia ${ }^{3}$ " e foi publicada no jornal, em dezoito de suas edições ${ }^{4}$. Tendo em vista os limites deste texto e o objetivo proposto, algumas temáticas e questões foram privilegiadas. No decorrer da análise, foi escolhido um conjunto de livros que sugere um projeto de formação integralista por meio da indicação de biografias edificantes, obras ensaísticas escritas por integralistas e outras, cujas temáticas estavam próximas ao discurso do movimento integralista.

Ao longo da publicação da coluna, houve um total de 34 indicações de livros, dentre elas, 32 obras diferentes e dois livros repetidos. No jornal, logo abaixo do nome dos livros indicados, um breve texto acompanhava as obras, destacando os aspectos da vida de seus autores, a qualidade gráfica do impresso, a importância da obra, a temática central abordada etc. Ao serem consideradas as abordagens de Roger Chartier e Robert Darnton, as indicações destas obras e seus comentários

3. No original, "Bibliographia". Todas as transcrições terão a sua ortografia atualizada, exceto os títulos dos livros.

4. A primeira edição do jornal tem data de 12 de setembro de 1936, e a última (ed. 69) é de os de fevereiro de 1938. Infelizmente, só foram encontradas 48 edições para a pesquisa presente. As edições 2, 8, 10, 13, 18, 19, $20,28,29,31,33,34,36,37,44,45,46,52,53,62$, e 67 não foram encontradas. $\mathrm{O}$ acesso ao conjunto dos textos ocorreu na Biblioteca Pública do Estado de Santa Catarina. 
são visualizados como parte de uma relação permeada por conflitos e interesses, possivelmente, para controlar a construção de sentido das obras e difusão de suas ideias, haja vista o objetivo do próprio jornal.

A análise presente trata a indicação e difusão dessas obras como uma prática formativa. Os livros são visualizados como artefatos nos quais estão representados valores, ideias e modelos de conduta; portanto, a sua publicação e difusão podem ser compreendidas como uma forma de formação. Segundo a autora Andréa Borges Leão:

Os livros são objetos preciosos no largo movimento de formação e interiorização da experiência do mundo, e a leitura é atividade bastante eficaz para a assimilação. (...). Quem difunde livros difunde ideias e valores, decide o que é permitido e o que é proibido existir, intervém na íntima estrutura das emoções formando sensibilidades. (LEÃO, 2007, p. 61).

Diante desta perspectiva, a coluna "Bibliografia”, além de ser considerada como uma "etapa" possível para o caminho dos livros aos leitores, deve ser analisada como um projeto de formação que priorizou uma série de obras consideradas como de maior relevância para os seus leitores potenciais.

\section{O periódico Flamma Verde, o Integralismo e a coluna}

\section{BIBLIOGRAFIA}

Flamma Verde foi um semanário que fez parte de um conjunto maior de outros jornais elaborados e difundidos por membros da Ação Integralista Brasileira (AIB), movimento e partido político que foi criado em outubro de 1932 pelo intelectual Plínio Salgado. Esse movimento existiu entre 1932 e 1938 e contou com a participação de diversos intelectuais em seus quadros, tais como Gustavo Barroso e Miguel Reale. A AIB teve expressiva participação em diversas cidades e estados brasileiros: foram eleitos prefeitos e vereadores "camisas-verdes" $\mathrm{e}$, segundo dados do próprio movimento, havia cerca 1 milhão de adeptos no auge de sua existência ${ }^{6}$. Tais dados, embora possam indicar certo grau de exagero, evidenciam também sua expansão ao longo do Brasil.

5. Os integralistas eram comumente chamados de "camisas-verdes", devido ao uso de uniforme da cor verde.

6. Salgado, em 1935, afirmou: "Somos hoje [1935] 1.000.00o de brasileiros que, em 3.000 núcleos que funcionam em todo o país, constituímos uma só família.” (SALGADO, 1935, p. 27 ). 
O protagonismo da leitura no projeto de formação integralista...

A AIB foi um movimento considerado de direita, de cunho autoritário, cujo lema era "Deus, Pátria e Família". Havia forte componente católico e nacionalista em seu objetivo de transformação da sociedade e criação de um estado uno e coeso, isto é, integral. Não por acaso, um de seus principais símbolos era a letra grega sigma $\sum$ que indica soma. Segundo os estudos realizados por Rosa Maria Feiteiro Cavalari: "Esse símbolo tinha como objetivo lembrar que o Movimento tinha o sentido de integrar todas as forças sociais do país na suprema expressão da nacionalidade". (CAVALARI, 1999, p. 191. Grifos da autora).

Com relação à emergência da AIB, de acordo com Marcos Chor Maio e Roney Cytrynowicz (2007), o ambiente do início do movimento foi marcado por imprevisibilidades no terreno político brasileiro. As indefinições doperíodo de 1930 a 1937 favoreceram o surgimento de "projetos radicais e mobilizantes que tentaram galvanizar a sociedade com a ideia de mudança" tal como a AIB. (MAIO; CYTRYNOWICZ, 2007, p. 41). Nesse sentido, além de fatores nacionais que contribuíram para a emergência da AIB e o seu desenvolvimento, deve-se levar em consideração também a influência do modelo externo de referência europeia. Sobre esse aspecto, segue-se a perspectiva do pesquisador Hélgio Trindade que ressalta: "Se a situação política interna do país proporciona condições ao surgimento de um movimento autoritário e antiliberal, o conteúdo e o estilo da organização do integralismo, entretanto, inspiram-se amplamente no fascismo europeu". (TRINDADE, 1979, p. 278).

Com relação à forma como o movimento visualizava suas próprias ações e o seu papel junto à sociedade, em diversos textos e outras publicações integralistas, é comum encontrarem-se falas e escritos que associavam a ação dos "camisas-verdes" a uma espécie de missão divina educativa de revolução espiritual, a fim de elevar as virtudes brasileiras e salvar a pátria. Segundo Plínio Salgado (1935, p. 15-16): "Conservamo-nos na linha realista, crentes de que uma obra sistemática de educação individual e das massas elevará a média das virtudes morais e cívicas do povo brasileiro, cuja estrutura íntima nos revela traços de superioridade incontestável."

Para a realização desse objetivo de renovação espiritual da Pátria, a imprensa foi usada de maneira sistemática e afirmativa pelos "camisas-verdes", a fim de divulgar suas ideias, arregimentar novos membros e universalizar sua doutrina ${ }^{7}$. O periódico Flamma Verde ${ }^{8}$ fez parte de um grande conjunto de jornais elaborados pelos inte-

7. Sobre a imprensa integralista, conferir Oliveira (2009) e Cavalari (1999).

8. Para uma discussão mais aprofundada referente aos objetivos desse jornal e mais questões, conferir, entre outros, os trabalhos de Gustavo Tiengo Pontes (2013) e João Henrique Zanelatto (2013). 
gralistas ou seus apoiadores. ${ }^{9}$ Nas páginas do jornal, foram constantes as matérias elogiosas ao papel do movimento junto à sociedade, as notícias referentes ao crescente número de adeptos, sobre sua expansão com a criação de novos núcleos e os textos laudatórios sobre o seu líder Plínio Salgado. Apesar de sua circulação, em princípio, estar proposta para todo o Estado de Santa Catarina, é possível supor que Florianópolis contou com uma presença muito mais significativa desse semanário, pois era a cidade sede da Chefia Provincial do Integralismo, o local de sua produção e a cidade referente na quase totalidade dos anúncios publicitários.

No jornal, a formatação da coluna permaneceu constante ao longo de sua publicação: acima da matéria, encontrava-se o título da coluna em destaque ("Bibliografia"), seguido, logo abaixo, pelo nome do livro indicado e também por um comentário sobre a obra indicada. Os nomes dos livros nem sempre apresentavam sua edição ou autoria; houve alguma variação nessa escrita. Com relação aos comentários, estes variavam de tamanho, mas permaneceram relativamente constantes em seu conteúdo: com elogios às obras, aos autores, materialidade dos livros etc. A seguir, um exemplo da coluna presente na edição de $n^{\circ} 4$ :

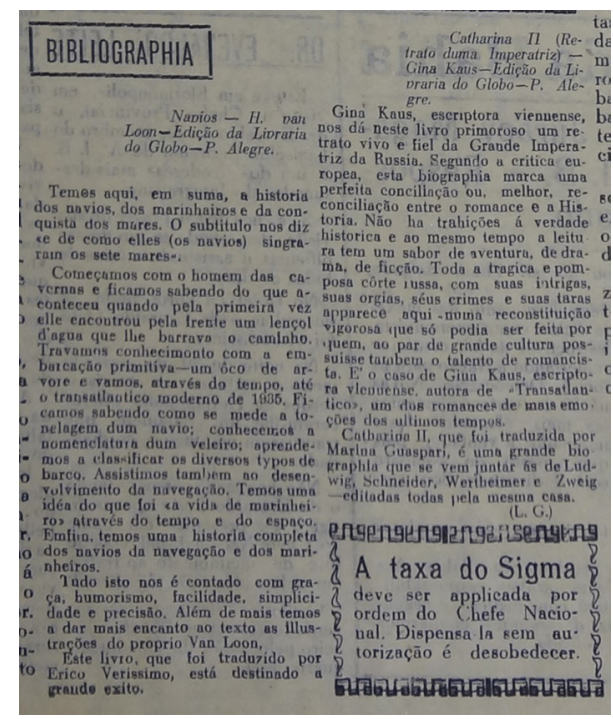

Figura o1 - Coluna "Bibliografia" presente na edição de no 4. Fonte: Flamma Verde, 03/10/1936, p. 2. Acervo: Biblioteca Pública do Estado de Santa Catarina.

9. O jornal publicava também alguns outros anúncios que buscavam divulgar livros. Tendo em vista os objetivos deste estudo, optou-se por analisar apenas as indicações da coluna "Bibliografia". 
O protagonismo da leitura no projeto de formação integralista...

Com a exceção de uma indicação que se trata de uma revista, todas as outras obras indicadas nessa seção foram editadas pela Livraria Globo, sediada em Porto Alegre. Foram 18 edições ${ }^{10}$ do jornal que indicavam algum livro. Assim, como foram encontradas 48 edições do periódico, cerca de $25 \%$ das edições contaram com a presença desta coluna. Essa quantidade significativa de anúncios pode ser mais bem compreendida tendo em vista o incremento das atividades da editora Livraria Globo nos anos de 1930 e 1940 e o incremento das atividades editoriais nacionais para esse mesmo momento ${ }^{11}$. É possível supor que a expansão da Livraria Globo tenha contribuído para uma maior aproximação entre esta e outros sujeitos ligados ao mercado de livros da capital catarinense. Ainda com relação à apresentação da coluna no jornal, não houve uma página fixa para sua veiculação. Com exceção da capa ou da contracapa do jornal, houve a veiculação da coluna "Bibliografia" em diversas páginas internas do Flamma Verde ${ }^{12}$.

OS LIVRos: GÊNERos DA NARRATIVA, VALORES E IDEIAS

Para compreender o papel da "Bibliografia" nesse periódico, é necessário discorrer tanto sobre os significados dos livros junto à sociedade como sobre a importância de uma coluna a eles dedicada em um jornal da época. Sobre esses aspectos, os estudos de Giselle Martins Venâncio e Maria Teresa Santos Cunha, assinalam:

Colecionar livros era uma etapa importante na formação de um intelectual. Possuir um gabinete de leitura, estantes cobertas de livros, uma quantidade de raridades ou de livros pertencentes aos cânones literários nacionais ou estrangeiros simbolizavam para os seus pares sua importância intelectual. (VENÂNCIO, 2006, p. 90).

O estudo dos jornais permite considerar que a leitura de seus artigos servia, também, para a circulação de modelos de comportamento desejados pela prescrição de normas de comportamento sociáveis que evidenciavam o avanço dos patamares de novas modalidades

10. As edições que contaram com alguma indicação foram: 1, 3, 4, 6, 7, 12, 15, 39, 47, 48, 54, 55, 56, 63, 64, 65 , 66 e 68 . 11. Sobre essa temática, ver Hallewell (2005) e Torresini (1999).

12. A quantidade de páginas do periódico variava de quatro a oito. Até a edição de número 43 (03/07/1937), havia o predomínio de quatro páginas, entre a edição 43 e a sua última, de número 69 (05/02/1938), a quantidade variou entre seis e oito páginas. 
de controle, autocontrole e comedimento que caracterizavam, nos anos 1930-40, uma elite em consolidação na capital catarinense. (CUNHA, 2011, p. 238).

É válido destacar o processo de aburguesamento que ocorreu em Florianópolis, durante a $1^{\text {a }}$ República. De acordo com o historiador Hermetes Reis de Araújo, nesse período houve uma série de reformas na capital catarinense e "um anseio por parte das elites locais em promover um amplo reajustamento social de sua população aos imperativos e às territorialidades burguesas de organização social” (ARAÚJO, 1989, p. 11). Nesse processo, cabia à imprensa, além da fixação de imagens, padrões de comportamentos e hábitos dessa elite, o papel de modelador de alguns costumes no campo de afirmação social da burguesia (ARAÚJO, 1989). Havia, portanto, uma busca por diferenciação social por parte de certos grupos de elite na capital catarinense, sendo os principais membros da AIB em Florianópolis provenientes das camadas médias ou superiores da sociedade ${ }^{13}$. Talvez seja possível sugerir que os livros fizessem parte de tal projeto e que a presença da coluna seja uma evidência também de um anseio de distinção social por parte dos responsáveis pelo periódico.

Em suma, levando em consideração um ambiente no qual certos grupos sociais de maior poder aquisitivo buscavam se diferenciar de outros segmentos da população, é possível supor que a presença da coluna sirva como um indício desse processo maior. "Bibliografia" pode sugerir que a difusão de livros adquiriu certa relevância, pois seus organizadores poderiam estar buscando se representar como leitores e guias na indicação de boas obras. Certamente, pode-se supor que a divulgação desses livros da Livraria Globo estivesse associada a interesses comerciais. No entanto, a veiculação da coluna não pode ser reduzida somente a esse aspecto. Pode-se também sugerir que a "Bibliografia" seja um indício de que leitores e outros responsáveis pelo jornal se interessassem em obter os benefícios simbólicos pela posse de livros, sua leitura e divulgação ${ }^{14}$.

A partir dessas considerações relacionadas à existência da coluna no periódico, volta-se a debater mais diretamente a apresentação dos livros nesse espaço. No caso das obras cuja autoria foi mencionada ou naquelas em que foi possível encontrar informações sobre isso, constatou-se que havia somente cinco mulheres no total

13. Cf. "Integralistas e Integralismo em Florianópolis" (PONTES, 2013, p. 89-119).

14. Para essa análise sobre benefícios simbólicos da posse de livros, foram tomadas como base as considerações expostas por Pierre Bourdieu, ao tratar do capital cultural objetivado. Cf. BOURDIEU, 2013, p. 79-88. 
de 24 autores. Em relação à nacionalidade destes, a maioria era de brasileiros, mas também havia austríacos, ingleses, estadunidenses, entre outros. No que se refere ao gênero dos livros da coluna "Bibliografia", apesar das dificuldades em "fixá-los" em categorias, por meio das noções apresentadas nos comentários, foi possível perceber que a maioria das indicações era de biografias de grandes personalidades, seguidas por livros de romances e de estudos sobre história. Apesar de os três gêneros serem os mais frequentes, houve também livros sobre poesias, livros técnicos, uma revista, relatos de viagem, ensaios etc.

No caso das biografias, o quadro a seguir apresenta os títulos indicados, edição, data e página da publicação:

\begin{tabular}{|l|c|c|}
\hline \multicolumn{1}{|c|}{ Título / Autor(a) } & Edição / Data & Página \\
\hline Leão XIII e o nosso tempo / René Fülöp-Miller & $1 / 12.09 .1936$ & 3 \\
\hline Erasmo de Rotterdam / Stefan Zweig & $3 / 26.09 .1936$ & 3 \\
\cline { 2 - 3 } & $6 / 17.10 .1936$ & 2 \\
\hline Catharina II: Retrato duma Imperatriz/ Gina Kauss & $4 / 03.10 .1936$ & 2 \\
\hline Leaders da Europa / Emil Ludwig & $12 / 28.11 .1936$ & 3 \\
\hline Christina da Suécia / Oskar Von Wetheimer & $54 / 25.09 .1937$ & 6 \\
\hline Simão Bolívar / Wolfram Dietrich & $64 / 01.01 .1938$ & 4 \\
\hline Carlos Magno e seus cavaleiros / s/nome & $68 / 29.01 .1938$ & 5 \\
\hline
\end{tabular}

Quadro o1 -Indicações biográficas na coluna "Bibliografia"

Além da veiculação de mensagens referentes às ilustrações, sobre a autoria das obras e suas qualidades gráficas, alguns aspectos relacionados à conduta das personalidades biografadas foram destacados ao longo dos comentários e podem ser relacionados a um modelo de formação direcionado aos leitores, o qual era baseado em virtudes morais e bons exemplos. Sobre isso, os comentários presentes nas obras "Erasmo de Rotterdam", “Carlos Magno..." e "Leão XIII...” são exemplares. No primeiro caso, em determinado trecho do comentário da edição $n^{\circ} 6$, está escrito que:

A figura do grande humanista holandês surge viva nesta biografia que há de fazer a delícia dos amigos de assuntos históricos. Segundo Zweig, Erasmo foi "o primeiro 
europeu consciente". Tolerante e amigo da liberdade, nunca fez aliança, nunca entrou em partidos. Ao cabo da leitura desta obra notável chegamos à conclusão de que Erasmo, pelo espírito, pertencia mais ao século vinte do que à sua época. (Flamma Verde, 17/10/1936, p. 2).

É possível constatar a valorização de um sujeito tolerante, amigo da liberdade e crítico da política do seu período. Com as devidas proporções, o discurso integralista parece estar próximo do veiculado nesta coluna, pois os "camisas-verdes" mostravam-se críticos dos partidos políticos existentes e engajados em uma missão de moralizar a sociedade e de elevar suas virtudes morais.

Convém notar também como Erasmo não é valorizado por seu engajamento político, mas por ser um "modelo de tolerância, respeito à liberdade e desejo de compreensão" (Flamma Verde, 26/o9/1936, p. 3), conforme escrito na terceira edição desse livro. Talvez a relevância dada a esses valores possa ser mais bem compreendida diante do discurso conservador integralista, segundo o qual, por exemplo, diferenças de classes não eram tratadas como um problema. Além disso, havia especial atenção às instituições tradicionais, sendo a defesa da igreja católica uma temática central do movimento.

Sob aspecto religioso, as indicações Carlos Magno e seus cavaleiros e Leão XIII e o Nosso Tempo são exemplares. No primeiro caso, o livro é indicado para crianças de 8 a 14 anos, sendo Carlos Magno apresentado como "o mais poderoso monarca do seu tempo" e "célebre defensor da fé cristã" (Flamma Verde, 29/o1/1938, p. 5). No segundo, Leão XIII, mesmo antes de se tornar Papa, era "uma das personalidades mais eminentes da corte papal. Muito ativo, estava em termos de boa amizade com a maioria dos países europeus. Escreveu poemas e fez várias cartas encíclicas.” (Flamma Verde, 12/o9/1936, p.5). Observe-se a temática religiosa católica sendo privilegiada novamente. A escolha para a difusão dessas obras deve ser desnaturalizada e considerada como parte de um processo de seleção e recorte temático realizado pelos responsáveis pelo jornal.

Entre outros livros indicados, também havia obras escritas por integralistas e outras cujos comentários buscavam ligá-las às ideias do movimento. A seguir, um quadro sobre essa temática: 
O protagonismo da leitura no projeto de formação integralista...

\begin{tabular}{|l|c|c|}
\hline \multicolumn{3}{|c|}{ Obras escritas por integralistas } \\
\hline \multicolumn{1}{|c|}{ Título / Autor(a) } & Edição / Data & Página \\
\hline $\begin{array}{l}\text { Nacionalismo - O Problema Judaico e o } \\
\text { Nacional-Socialismo / Anor Butler Maciel }\end{array}$ & $48 / 14.08 .1937$ & 4 \\
\hline A Questão Judaica / Padre José Cabral & $63 / 24.12 .1937$ & 3 \\
\hline \multicolumn{2}{|c|}{ Obras cujos comentários associam-nas ao discurso da AIB } \\
\hline $\begin{array}{l}\text { Estudantes, Amor, Tscheka e Morte / Alia } \\
\text { Rachmanova }\end{array}$ & $14 / 12.11 .1936$ & 3 \\
\hline China, Velha China / Pearl S. Buck & $54 / 25.09 .1937$ & 6 \\
\hline
\end{tabular}

Quadro 02 - Obras escritas por integralistas e cujos comentários associam-nas ao discurso da AIB

No caso do livro Nacionalismo - O Problema Judaico e o Nacional-Socialismo, o comentário, além de apresentar o autor como um "adepto ardoroso da doutrina integralista”, afirma que o livro trata da história dos judeus no Brasil. É exposto que a obra de Gustavo Barroso é exaltada no decorrer das páginas e que, nesse livro, A. B. Maciel "ataca de frente o problema do judaísmo, mostrando o perigo que constitui para o Brasil a crescente influência do elemento israelita na vida íntima nacional” (Flamma Verde, 14/o8/1937, p. 4). Além disso:

Nas 150 páginas do livro [...] o sr. Anor Butler Maciel, empregando sempre um estilo claro e atraente, demonstra não ser um espírito conturbado por qualquer fanatismo, mas um profundo conhecer dos problemas sobre os quais discorre com tanta proficiência". (Flamma Verde, 14/o8/1937, p. 4).

Em A Questão Judaica, ocorre um processo semelhante: o livro é apresentado como "pensado e documentado, sem excessos nem demasias" e de grande importância para o momento no qual o Brasil "mobiliza todas as forças conservadoras para a repressão das doutrinas marxistas”. É dito também que apresenta um prefácio de Gustavo Barroso e sua leitura "recomenda-se principalmente àqueles que veem no judaísmo um perigo nefasto para a estabilidade social das nações e para a civilização cristã." (Flamma Verde, 24/12/1937, p. 3).

Essas indicações demonstram parte do esforço da imprensa integralista para divulgação de suas ideias. Nesse caso, o livro é visualizado praticamente como uma 
"ferramenta" para guiar os seus leitores na "luta" contra os inimigos da pátria. É um crivo de leitura que parece pressupor e trabalhar a favor de um engajamento político constante num período descrito como de ameaça para o Brasil. Importante sublinhar, também, o tratamento para seus autores e as obras, considerados, ao longo dos comentários, como estudos sérios e de escrita exemplar, isto é, práticas a fim de elevar a importância das obras e seus autores.

Semelhante a essas indicações escritas por integralistas, outras duas obras apresentaram também comentários que as vincularam a uma das principais temáticas divulgadas pelo integralismo: o anticomunismo. São eles, Estudantes, Amor, Tscheka e Morte e China, Velha China. O primeiro é descrito como um diário narrado por uma estudante russa entre os meses próximos e posteriores à Revolução Russa de 1917. Após o comentário, que realça um momento no qual "a morte [está] solta nas ruas" devido à Revolução, reforça-se que, por se tratar de um diário, o livro é "baseado em fatos, porque visto sem paixão política" e afirma-se:

Este livro deve ser lido por todos os integralistas e aqueles que quiserem conhecer a hediondez do terror bolchevista. / Pedidos à Secretaria Provincial de Propaganda mediante a remessa de oito mil réis, ( $7 \$ 000$ custo do exemplar e $1 \$ 000$ para registro). (Flamma Verde, 12/11/1936, p. 3).

No caso de China, Velha China, trata-se de um livro baseado em observações de viagem de sua autora, que viveu por muitos anos na China e "soube descrever os sentimentos mais ocultos dessas criaturas de rostos pálidos e impassíveis, para nós sempre misteriosas." Ao final do comentário está escrito:

Há algumas cenas que mostram a revolta que havia entre as classes pobres das grandes cidades, o trabalho dos propagandistas vermelhos e a revolução chinesa espalhando o terror e a miséria entre as populações miseráveis dos campos. (Flamma Verde, 25/09/1937, p. 6).

Conforme exposto, observa-se uma busca de controle da produção de sentido dessas obras, na qual a chave de leitura proposta em seus comentários prioriza a temática anticomunista. $\mathrm{O}$ modo de divulgação dos livros pode ser visualizado, portanto, como parte de um esforço integralista de combate aos seus inimigos, ilustrando, com essas indicações, exemplos de ações dos considerados "vermelhos". 
O protagonismo da leitura no projeto de formação integralista...

No caso do livro de Rachmanova, convém sublinhar sua importância também pela imposição do diário como uma leitura obrigatória pelos integralistas, ou seja, a recomendação do livro pode ser compreendida como parte de um trabalho de difusão do "perigo" que são as ações comunistas, o que contribui também para elaboração de uma espécie de identidade integralista, a partir do combate de seus adversários tratados como inimigos.

Além dessas temáticas, quando se retoma o gênero biografias, outra obra que merece destaque é Simão Bolivar, na qual seus atos são heroicizados devido ao seu papel como "criador de tantas nações" e por ter sido "a mais eminente figura que a América Latina ofereceu à História” (Flamma Verde, o1/o1/1938, p. 4). Convém notar como sua figura é exaltada como um modelo de luta e libertação política da América Latina, devido a sua importância histórica para o continente. Nesse período de discussões da temática nacional e diante de diversos acontecimentos, como a $1^{\mathrm{a}}$ Guerra Mundial, o Centenário da Independência e o Movimento Modernista ${ }^{15}$, talvez a escolha dessa publicação possa ser vista como um indício também destes debates: a necessidade de se discutir a temática nacional, um modelo de herói para a renovação nacional e o papel do intelectual como engajado na luta política.

\section{Biografias DE MULHERES NA COLUNA}

Outra questão a ser explorada no caso das biografias decorre de um tratamento diferenciado prestado às biografias de mulheres: Christina da Suécia e Catharina II: Retrato duma Imperatriz. Nos comentários presentes nessas duas obras, são destacados certos aspectos e qualidades não presentes nos comentários de outras personalidades masculinas. Com a exceção à indicação Leaders da Europa, em que os biografados homens são tratados, num breve comentário, somente como "vultos destacados da Europa Contemporânea” (Flamma Verde, 28/11/1936, p. 3), nos outros casos, as virtudes, ações políticas e outras qualidades dos sujeitos masculinos são realçadas, tendo em vista, principalmente, suas ações. Em contraposição a essa recorrência, nos comentários que seguem as duas biografias femininas, a importância das personagens é somente revelada pelo tratamento de Catharina II como "Grande Imperatriz da Rússia". Nas duas biografias sobre mulheres, os comentários realçam aspectos pessoais das duas figuras. A exemplo, no caso de Christina, esta é

15. Sobre este assunto, cf. VELLOSO (2010). 
apresentada como uma "das figuras mais misteriosas e singulares da História. (...) Essa criatura romântica e enigmática se apresenta até hoje como uma incógnita" (Flamma Verde, 25/o9/1937, p. 6). Já em Catharina II..., lê-se que, neste livro "sem traições à verdade" e de leitura com "sabor de aventura, de drama, de ficção": "Toda a trágica e pomposa corte russa, com suas orgias, seus crimes e suas taras aparecem [...] numa reconstituição vigorosa [...]". (Flamma Verde, 7/10/1936, p. 2).

Em ambos os livros que tratam de biografias de mulheres, a importância das obras não decorre da escolha por suas personagens, pois, de acordo com os comentários da coluna, os mistérios do período e das biografadas são priorizados com fins de divulgação. Logo, é possível sugerir um tratamento diferenciado entre homens e mulheres, o qual contribui para uma perspectiva que reforça a associação tradicional entre mulheres e questões pessoais ou de âmbito privado. Em outras palavras, a partir dos comentários, há um modelo de formação em que virtudes e ações políticas parecem exaltadas nos homens e, contrariamente, as mulheres têm sua importância diminuída.

\section{CONSIDERAÇões Finais}

Conforme observado por R. Darnton e R. Chartier, os livros são objetos de interesse, e diferentes leituras competem entre si em busca de se apresentarem como as mais corretas ou relevantes. As considerações desses autores devem ser relembradas quando se objetiva explicitar o conflito de interesses em torno das obras, ao mesmo tempo em que se lembra que a prática de leitura não se resume àquilo que um comentador ou crítico destacou como a produção de conhecimento autorizada e correta de um determinado livro. Essas questões demonstram o quanto a teoria da produção do conhecimento histórico refina a prática de pesquisa e auxilia a desnaturalizar práticas do cotidiano.

Com relação aos livros indicados na coluna em debate, no decorrer deste artigo, buscou-se levantar questões acerca de qual modelo/projeto de formação foi proposto a partir dessas obras. A investigação de um conjunto de indicações evidenciou um projeto formativo no qual as virtudes morais são elevadas, a temática religiosa católica é priorizada e uma situação de perigo é disseminada no país, a partir da ameaça dos judeus e comunistas. Portanto, essa difusão evidenciou também o uso de livros como uma ferramenta de transmissão das ideias do movimento. 
O protagonismo da leitura no projeto de formação integralista...

Nesse sentido, as biografias ressaltam um ideal de homem com virtudes morais e ativo politicamente, em contraposição a mulheres, cuja importância estão ou na sua apresentação como figuras misteriosas, ou a partir de aspectos interessantes de sua personalidade e da época em que viveram. Ou seja, há um projeto formativo tradicional que reforça a associação entre os homens e o ambiente público e entre as mulheres e o ambiente privado. Logo, havia um modelo/projeto de formação que privilegiava o caráter exemplar proposto nas biografias edificantes e nas ideias nacionalistas e patrióticas que deveriam guiar a política do país em diversos aspectos.

\section{REFERÊNCIAS}

ARAÚJO, Hermetes Reis de. A invenção do litoral: reformas urbanas e reajustamento social em Florianópolis na Primeira República. Dissertação (Mestrado em História). Pontifícia Universidade Católica de São Paulo, São Paulo, 1989.

BOURDIEU, Pierre. Os três estados do capital cultural. In: NOGUEIRA, Maria Alice; CATARINA, Afrânio (Org.). Pierre Bourdieu: escritos de educação. Petrópolis: Vozes, 2013. p. 79-88.

CAVALARI, Rosa Maria Feiteiro. Integralismo: ideologia e organização de um partido de massa no Brasil (1932-1937). Bauru, SP: EDUSC, 1999.

CHARTIER, Roger. A ordem dos livros: leitores, autores e bibliotecas na Europa entre os séculos XIV e XVIII. Trad. Mary del Priore. Brasília: Universidade de Brasília, 1998.

CUNHA, Maria Teresa Santos. Mensageiro de sociabilidades: estudo sobre um jornal escolar infantil (1946-52). In: MORGA, Antonio Emílio (Org). História, Cidade e Sociabilidade. Itajaí: Casa Aberta Editora, 2011. p. 235-250.

DARNTON, Robert. O Beijo de Lamourette: mídia, cultura e revolução. Trad. Denise Bottman. São Paulo: Companhia das Letras, 2010.

FLAMMA VERDE. Florianópolis, SC: Ação Integralista Brasileira, 1936-1938. (Biblioteca Pública do Estado de Santa Catarina).

HALLEWELL, Laurence. O Livro no Brasil: sua história. Trad. Maria da Penha Villalobos, Lourenço de Oliveira Lólio e Geraldo Gerson de Souza. São Paulo: Editora da Universidade de São Paulo, 2005. LEÃO, Andréa Borges. Norbert Elias e a Educação. Belo Horizonte: Autêntica, 2007.

MAIO, Marcos Chor; CYTRYNOWICZ, Roney. Ação Integralista Brasileira: um movimento fascista no Brasil (1932-1938). In: FERREIRA, Jorge; DELGADO, Lucilia de Almeida Neves (Org.). O Tempo do Nacional-estatismo: do início da década de 1930 ao apogeu do Estado Novo. Rio de Janeiro: Civilização Brasileira, 2007. p. 41-61.

OLIVEIRA, Rodrigo Santos. Imprensa Integralista, Imprensa Militante (1932-1937). 2009. Tese (Doutorado em História) - Programa de Pós-Graduação em História, Pontifícia Universidade Católica do Rio Grande do Sul, Porto Alegre/RS, 2009.

PONTES, Gustavo Tiengo. Adeptos do Sigma em Florianópolis: estudo sobre o periódico 'Flamma Verde' e a presença integralista na capital catarinense. 2013. Monografia de Conclusão de Curso (História), Universidade Federal de Santa Catarina, Florianópolis/SC, 2013. 
SALGADO, Plínio. A doutrina do Sigma. Rio de Janeiro: Schmidt, 1935.

TORRESINI, Elizabeth Wenhausen Rochadel. Editora Globo: uma aventura editorial nos anos 30 e 40. São Paulo: Editora da Universidade de São Paulo; Porto Alegre: Editora da Universidade UFRGS, 1999.

TRINDADE, Hélgio. Integralismo: o fascismo brasileiro na década de 30. São Paulo, Rio de Janeiro: Difel, 1979.

VENÂNCIO, Giselle Martins. Da escrita impressa aos impressos da biblioteca: uma análise da trajetória de leitura de Francisco José de Oliveira Vianna. In: DUTRA, Eliana de Freitas; MOLLIER, JeanYves (Org.). Política, Nação e Edição: o lugar dos impressos na construção da vida política. Brasil, Europa e Américas no século XVIII e XX. São Paulo: Annablume, 2006. p. 87-108.

VELLOSO, Mônica Pimenta. História \& Modernismo. Belo Horizonte: Autêntica Editora, 2010.

ZANELATTO, João Henrique. Anauê, Alvorada e Flamma Verde: a imprensa integralista e as disputas pelo poder político em Santa Catarina. Passagens. Revista Internacional de História Política e Cultura Jurídica. Rio de Janeiro: vol. 5, n. 3, p. 377-396, set.-dez. 2013.

\section{SOBRE OS AUTORES}

Gustavo Tiengo Pontes é graduado em História (Universidade Federal de Santa Catarina), Mestre em Educação/História e Historiografia da Educação (Universidade do Estado de Santa Catarina). É doutorando em História pela Universidade Federal de Santa Catarina e Professor de História pela rede pública do Estado de Santa Catarina no Colégio Pero Vaz de Caminha. Tem pesquisa sobre a Ação Integralista Brasileira e periódicos, e desenvolve pesquisa de doutorado sobre o campo de produção de periódicos na cidade de Florianópolis na década de 1930. E-mail: gustavotpontes@gmail.com

Maria Teresa Santos Cunha é graduada e tem Mestrado em História (Universidade Federal de Santa Catarina) e Doutorado em Educação/História e Filosofia (Universidade de São Paulo). É Professora do Departamento de História da Universidade do Estado de Santa Catarina e dos Programas de Pós-Graduação em Educação e Pós-Graduação em História dessa Universidade. Tem experiência na área de História, com ênfase em História Cultural e História do Tempo Presente, atuando nas seguintes áreas: História da Leitura e da Cultura Escrita, História da Educação, Acervos Pessoais e Patrimônio Cultural. Foi Coordenadora Nacional do Grupo de Trabalho de História da Educação da Associação Nacional de Pesquisa e Pós-Graduação em Educação - ANPEd/ Out. 2009 - 2011. Foi Integrante Titular do Conselho Interdisciplinar de Pesquisa e Editoração (CIPE) 
O protagonismo da leitura no projeto de formação integralista...

da Fundação Biblioteca Nacional/Rio de Janeiro/Ministério da Cultura/2011 a 2013 e Editora das Revistas Linhas e Tempo e Argumento, na UDESC, entre 2013 e 2016. Atualmente exerce a Vice-Coordenação do Programa de Pós-Graduação em História do Tempo Presente na Universidade do Estado de Santa Catarina. É Bolsista Produtividade em Pesquisa do CNPq.

E-mail: mariatsc@gmail.com

Recebido em 19 de fevereiro de 2016 e aprovado em 15 de dezembro de 2016. 